\title{
Ealurial
}

\section{Estudos de Caso na Pesquisa Acadêmica em Turismo}

No trabalho intitulado "Realidade Turística nas Pesquisas Científicas", Rejowski (1997) analisa a produção de dissertações e teses de 1973 a 1995 sob três enfoques: caracterização geral, análise disciplinar e temática, e análise por tipo de pesquisa e estudo. Com relação a esteúltimo aspecto, identificapesquisas exploratórias, descritivas e/ou explicativas e, dentro dessas, vários tipos de estudo, sendo um deles o chamado estudo de caso.

Nesse trabalho, os estudos de caso aparecem como tipo de pesquisa em cerca de $33 \%$ da produção acadêmica do período, ou seja, em 34 dissertações e teses. Destas, 33 erampesquisasexploratóriase 1 erapesquisa exploratório-descritiva. Tais estudos sugerem a realização de uma primeira abordagem do problema, a partir do enfoqueem caso(s) de estudo - região, cidade, local, instituição, grupo, organização, situação etc. Normalmente diagnosticam o problema indicando soluções (Rejowski, 1997:27,78-80).

Ao contrário do que pode em princípio parecer, não se trata aqui de abordagem superficial e/ou supérflua de uma temática. Segundo Dencker (1998: 127), estudo de caso é "o estudo profundo e exaustivo de determinados objetos ou situações", permitindo "o conhecimento em profundidade dos processos e relações sociais". Nesse sentido, Sakata (2002: 27) considera-o como a

análise de um ambiente social específico ou de um aspecto social em particular dentro de um ambiente social. Constituem investigações aprofundadas de uma dada unidade social resultando em uma completa e bem organizada representação desta unidade.

De forma mais apropriada pode-se considerar o estudo de caso como estratégia de pesquisa (ao invés de tipo), podendo se referir a um único caso ou a múltiplos casos (Yin, 1994); possibilita grande flexibilidade, mas não permite a generalização dos resultados. Seus objetivos podem ser a descrição, a classificação (desenvolvimento de tipologia), o desenvolvimento teórico e o desenvolvimento limitado da teoria. Para Bonoma ( apud Bressan, 2002), seu objetivo é a compreensão.

Nas Ciências Sociais há profusão da utilização de estudos de caso nas pesquisas científicas, principalmente no contexto do estágio inicial do conhecimento científico em Turismo. Trazem importante contribuiçãoà evoluçãodesseconhecimento, na medida em que tiver sido bem planejado e conduzido.

Dos sete artigos constantes desta publicação, dois se configuram como 
análises: um aborda o tema Turismo, Hotelaria e Hospitalidade através da análise crítica e reflexiva sobre o surgimento dos cursos de Hotelaria e o uso da denominação Hotelaria ou Hospitalidade no Brasil; o outro, traça a trajetória do planejamento estatal, em especial no Nordeste, e seus reflexos no planejamento do turismo. Já os demais, retratam cinco estudos de caso(s), sendo três referentes a um único caso e dois a múltiplos casos:

um hotel de médio porte de Recife, pertencente a uma cadeia internacional, abordando a gestão de recursos humanos sob a ótica do marketing interno; uma empresa aérea recente de baixo custo - Gol -, analisando suas estratégias e sua política de preços no mercado de aviação no Brasil;

uma aliança estratégica institucional entre o Sistema de Informação Geográfica de Zulia (SIGTUR-Zulia) e a ContaSatélite de Turismo da Venezuela, analisando os recursos humanos, físicos e econômicos para sua viabilidade;

- duas agências de turismo-Stella Barrose CVC-,tratandoda satisfaçãodo cliente em relação à oferta de serviços;

- três "clusters" turísticos - Sul da Austrália, Costa Rica e Nordeste Brasileiro -, abordados como formas de configuração do turismo no ambiente globalizado.

Este conjunto de trabalhos confirma a significativa produção de estudos de caso centrados em diferentes empresas turísticas, em situação e em regiões, que, tanto pela temáticas tratadas quanto pelo desenvolvimento das suas abordagens, trazem importantes contribuições ao estudo do Turismo. A isto somam-se os outros dois artigos que se utilizam de outras estratégias de pesquisa, igualmente bem conduzidas. Além dos artigos, este fascículo apresenta cinco resenhas de livros recentemente lançados na área de turismo, as quais foram elaboradas pelos alunos do Mestrado em Turismo, da Universidade de Caxias do Sul, como exercício prático da disciplina "Evolução da Pesquisa Turística no Brasil".

Mirian Rejowski

Editora

\section{Referências}

BRESSAN, F. 2002. O método do estudo de caso. Disponível em: <www.aurbana.hpg.ig.com.brl metodo.htm> Acesso em: 11 jul. 2002.

DENCKER, A. F. M. 1998. Métodos e técnicas da pesquisa em turismo. São Paulo: Futura. REJOWSKI, M. 1997. Realidade turística nas pesquisas científicas. Visão de pesquisadores e profissionais. Tese (Livre Docência)- Escola de Comunicações e Artes, Universidade de São Paulo. V. I.

SAKATA, M. C. G. 2002. Tendência dos tratamentos metodológicos da pesquisa acadêmica em lazer (turismo). São Paulo: ECA-USP. (Relatório de Exame de Qualificação de Mestrado).

YIN, R. 1994. Case study research. Design and methods. 2 ed. ThosandsOaks: Sage. 